\title{
Determinants of Short Birth Interval Among Married Women of Child Bearing Age in Becho Woreda, South West Showa Zone, Oromia Region, Ethiopia
}

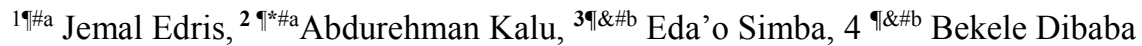 \\ $1 \#$ a Public health expertise at save the children, Southwest Shoa Zone, Ethiopia \\ ${ }^{2 \# a}$ Department of Public Health, College of Health Science, Arsi University, Asella, Ethiopia \\ ${ }^{3 * b}$ Eda'o Simba \\ Department of Public Health, College of Health Science \\ Madda Walabu University, Shashamane Campus, Shashamane, Ethiopia \\ $4 \pi^{\pi \& \# b}$ Bekele Dibaba \\ ${ }^{2 \# a}$ Department of Public Health, College of Health Science, Arsi University, Asella, Ethiopia
}

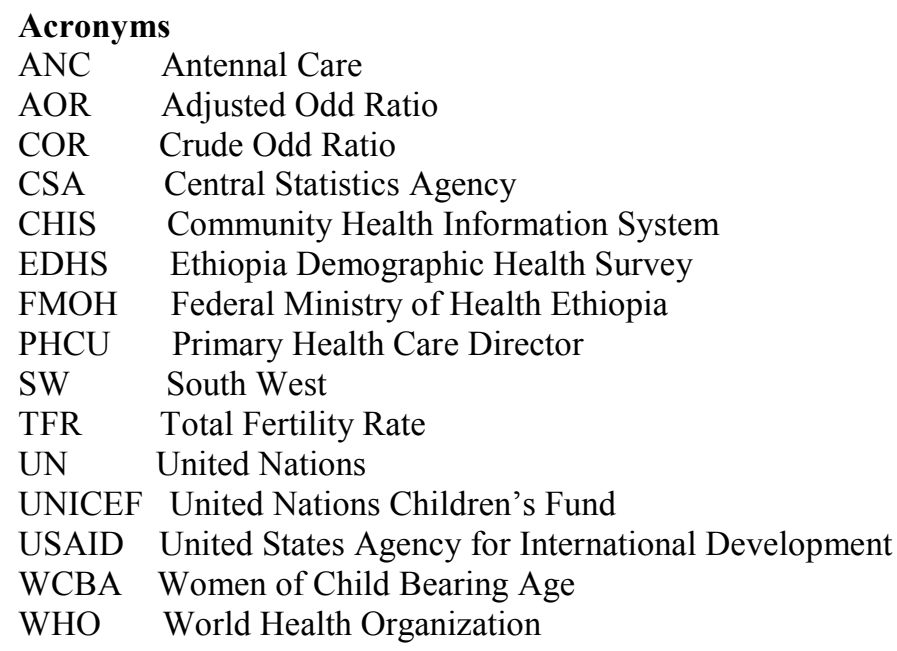

\begin{abstract}
Background: Short Birth interval is the time duration less than 33 months between two consecutive live births. Short birth interval is one of the concerns of different countries of the world, because it can affect the overall economic, political and social aspects of a given country by increasing their fertility. Women in the developing world who have many children in quick succession place themselves and their children at enormous risks. Child bearing patterns-maternal age, birth order, and the interval between births-have an important influence upon the probability that a child will survive infancy and early childhood. Thus the study area has short birth interval below the national and WHO recommendation.

Objective: To identify determinants of short birth interval among married women of child bearing age in Becho Woreda.

Methods and materials: Community based case control study was conducted from July to October 2019. Cases $(n=231)$ were women with short birth intervals less than 33 months), whereas controls $(n=462)$ were women having history of birth intervals (33 to 59 Months) selected by systematic random sampling. Data were collected using structured interviewer administered questionnaires then cleaned, coded, entered and analyzed by using SPSS version 22. Frequency distributions, measures of central tendency and logistic regression were calculated and interpreted accordingly.

Result: Result of this study revealed that $60.3 \%$ of respondents had information about short birth interval and $65.4 \%$ of respondents have utilized previous pregnancy plan. Age of mother at first child birth, the number of children, her educational level, wealth index, occupation of the mother, and duration of breast feeding and use of modern contraceptive were the determinant of optimum birth interval. Having no formal education $[(\mathrm{AOR}=2.04$, $95 \% \mathrm{CI} ;(1.49-2.78)]$, duration of breastfeeding for less than 24 months[(AOR $=0.62,95 \% \mathrm{CI}$; $(0.45-0.84)]$, preceding child being female $[(\mathrm{AOR}=7.69,95 \% \mathrm{CI} ;(5.24-11.30)]$, modern contraceptive use [(AOR=7.07, 95\% CI: (5.03-9.94)], poor wealth index [(AOR=3.08, 95\% CI; (1.85-5.14)] and Previous pregnancy plan [(AOR= $8.59,95 \% \mathrm{CI} ;(6.02-12.18)]$ of respondents were independent predictors of short birth interval.

Conclusion and recommendation: Educational status, duration of breast feeding, sex of the preceding child, modern contraceptive use and wealth index were markers of unequal distribution of inter birth intervals. Ministry of Health should work on women and their partner on creating awareness about the importance of modern
\end{abstract}


contraceptive utilization, breast-feeding, and optimal birth interval.

Keywords: Birth interval; Child bearing age; Determinants; South West Shoa

DOI: $10.7176 / \mathrm{JHMN} / 87-01$

Publication date:March $31^{\text {st }} 2021$

\section{Introduction}

\subsection{Background}

Short birth interval is time duration less than 33 months between two consecutive live births. The high fertility rate is one of the concerns of the world, because it can affect the overall economic, political and social aspects of a given country. In addition, high fertility is also burden on health $\mathrm{n}$ as it has serious implications on the health of mothers and children (Tessema et al., 2015).

Women in the developing world who have many children in quick succession place themselves and their children at enormous risk. Child bearing patterns-maternal age, birth order, and the interval between births-have an important influence upon the probability that a child will survive Infancy and early childhood. Birth or child spacing has a particular significance for child survival. Studies show that when the length of time between two births in a family is less than two years, the new-born, on average, is twice as likely to die in infancy as might a child born after a longer birth-interval. This applies not only to the first year of life, but adversely affects the child's survival chances for at least the first four years of life. Babies born after a three-to-four years interval have the best chances of survival (Towriss et al., 2018).

Ethiopia is the second most populous country in Africa with total fertility rate of 4.6 (2.3 for Urban and 5.2 for rural)( (Survey and Findings, 2016). High proportion of reproductive age women (58\%) was illiterate in Africa. With this very low literacy rate, the contraceptive prevalence of Ethiopia is about only $35 \%$. Currently, there is improvement in total fertility rate (TFR) reduction from 5.8 in 2000 to 4.6 in 2016. But, the change in fertility is not consistent throughout the country's region and society. According to the data from 2016 Ethiopian demographic and health survey, out of 20 live births, one child dies each year before its first birth day. Optimal birth interval is the main strategy of health promotion program for mothers and children, and the important indicators of fertility scenario of the country. Because of its implication for fertility and for maternal and child health, optimal birth interval has got attention in demography and public health research (Survey and Findings, 2016).

The recommended optimal duration of the birth interval is not agreed upon by different researchers. Some studies recommend that a minimum birth to birth interval should be 27 months and the maximum interval should be 59 months. But, World Health Organization technical consultation on birth spacing recommended inter birth interval of at least 33 months before a women deliver the next child. This recommendation was based on aims to reduce the risk of adverse maternal, perinatal and infant outcomes (Mrema et al., 2016)

Studies supported by the United States Agency for International Development have suggested that optimal birth spacing of three to five years is more advantageous. These studies confirmed that in less developed countries if no births occur within thirty-six months of a preceding birth, infant mortality and under-five mortality rates would drop by $2 \%$ and $35 \%$ respectively (Towriss et al., 2018).

A short birth interval is known to have negative effects on maternal, perinatal and neonatal outcomes as well as on child health. The hypothetical causal mechanisms which explains the association between short interbirth intervals and adverse outcomes were: maternal nutritional depletion, folate depletion, cervical insufficiency, vertical transmission of infections, suboptimal lactation related to breastfeeding-pregnancy overlap, sibling competition, transmission of infectious diseases among siblings, incomplete healing of uterine scar from previous cesarean delivery, and abnormal remodeling of endometrial blood vessels (Barclay and Kolk, 2018).

Longer intervals between consecutive births decrease the number of children a woman can have, this results in beneficial effects on the health status of mothers and their children. A longer interval between consecutive births has a greater advantage in reducing abortions, complication related to unsafe abortion and unwanted pregnancies. It also improves children's development by improving the nutritional status of the preceding child. The community-based cross-sectional study conducted among 3600 women ever gave live births in North Gondar in 2010 indicated that for every additional pregnancy, the risk of neonatal death was 2.5 and majority of deaths were contributed to the premature birth and underweight at delivery (Tessema et al., 2013).

Meta-analysis study in 2017 from Ethiopia showed that Short birth intervals substantially reduce children's chances of survival, especially if the interval is less than two years. For example, according to data from Ethiopian Demographic and Health Survey of 2016, children born less than two years after the preceding birth were 2.5 times more likely to die within the first year of life and within the first five years of life compared to children born three years after the preceding birth. So, by promoting the length of the birth interval to at least two years we can reduce under-one mortality by half (Innes et al., 2019).

A meta-analysis was done using 52 demographic and health survey data from developing countries; Latin America, Asia, Africa and Middle East countries indicated that compared with a preceding birth-to-pregnancy 
interval of greater than 36 months, children conceived with interval durations of less than 24 months have significantly higher risks of mortality (Innes et al., 2019).

In general, previously conducted studies in different parts of developing and developed countries have proved that short birth intervals have an impact on maternal and child health. However, few studies conducted to assess factors contributing to a short birth interval in Ethiopia have some limitations. For instance, almost all the previous studies measured the duration of birth interval. This could not identify the contributing factors of short birth interval (Begna et al., 2013a).

In addition, this specific study area also lacks information on determinants of birth interval, which is not addressed well for further intervention. In addition, understanding the practice of birth interval and its determinants is helpful to design evidence-based strategies for interventions in this study area. Understanding factors which influence women inter birth interval is critical for countries like Ethiopia with a population policy aiming at reducing fertility.

\subsection{Statement of the Problem}

Short birth interval is the major contributors of maternal and infant mortality particularly in developing countries like Ethiopia. It places a heavy burden over the shoulders of family economy and health condition in particular and nation's economic development in general. Practice of adequate birth interval between successive pregnancies is a proven measure in combating maternal and infant mortality (Mace and Sear, 2015).

In fact, the WHO estimates that 1 out of every 22 women in Africa die from pregnancy related complications. Ethiopia has one of the highest maternal mortality ratios in Africa and the world, estimated at 412 per 100,000 live births in 2016. Women in developing countries have shorter birth intervals than they would prefer. The main reason for short birth intervals is that many women in developing countries do not use contraception after birth and therefore are likely to become pregnant once fecundity returns (Mrema et al., 2014)

Most African cultures value children highly. But few people-including women themselves understand the risks involved in bearing children. Women in Africa die much more frequently from complications of pregnancy and child birth than women in Europe and North America. In Sub-Saharan Africa, these complications are sometimes the most common cause of death for women of child bearing age (Innes et al., 2019).

Adequate child spacing is considered as a positive factor on the health of mothers and their children. The birth interval has been reported to have significant effect on the child's future physical and mental capabilities. It has also been shown to affect the health of mothers. Pregnancy and child birth are major determinants of women's health. In developing countries, complications of pregnancy and delivery account for about one quarter of all deaths among women of reproductive age. Both short and long inter pregnancy intervals have been associated with low birth weight, preterm delivery, and delivery of a small for gestational age infant. The increased risk of adverse pregnancy outcomes related to short inter pregnancy intervals has been attributed to a number of mechanisms including maternal depletion, hormonal imbalance, and postpartum stress (Youssef, 2015).

The new evidence makes child spacing compelling as a health issue of global and national importance. The rationale for increased attention to birth spacing is evidence-based, the magnitude of the problem of too closely spaced births is enormous, and the demand and unmet need for birth spacing services are may be considerable. Almost all the previous studies measured the duration of birth interval and this could not identify the contributing factors of short birth interval. The other limitation is the intervention implemented so far was focusing only on the increasing utilization and service availability of family planning, but not focusing on the root cause of the short birth interval(Survey, 2016)

Thus, understanding factors which influence women inter birth interval is critical for countries like Ethiopia with a population policy aiming at reducing fertility. There is no study conducted so far to identify determine of birth interval in this particular area Becho woreda in South West Showa zone, Oromia region. And this study was aimed at assessing the determinant of short birth interval among married women of child bearing women at Becho woreda. This study could also be used as based line for further studies.

\subsection{Significance of the Study}

Birth spacing is practiced when a couple decide not to have too many children, when they want to reduce the frequency of child-birth, or when they do not want to have a child because the wife is too young or too old. In a considerable number of countries, couples have taken to practicing birth spacing. Birth spacing can protect the child and the mother against the danger of loss of life. It also improves both the health of the child and the mother. It promotes the happiness and health of the family, too

Almost all the previous studies were focused on measuring the duration of birth interval and this could not identify the contributing factors of short birth interval. Studies have not been conducted on such matters in the area and empirical evidence is very helpful to act on the problem locally. Thus acquiring research based knowledge of these problems is key step in undertaking appropriate intervention. 
This study, therefore, aimed at determine determinants of inter birth intervals among women of reproductive age in Becho woreda and will furnish important directions for intervention which help local health planners to critically look at the problem during their planning process. It is also hoped that the result of this research will be an input for regional Zone and woreda health care planners and program managers in designing site specific and scientifically sound interventions to address the gap in the utilization of family planning and optimal birth spacing. Finally, it is also expected to provide baseline information for further robust follow-up studies.

\subsection{Objectives}

\subsubsection{General Objective}

* To determine determinants of short birth interval among women of child bearing age in Becho woreda, South-west Showa zone, Oromia, Ethiopia, 2019.

\subsection{Operational Definition}

- Birth interval: the period between two consecutive live births.

- Cases: Systematically selected married women of child-bearing age with at least two consecutive deliveries and who have history of short birth intervals (birth interval of less than 33 months between two successive last births).

- Controls: Systematically selected married women of childbearing age who have at least two consecutive births and had a history of optimum birth intervals (birth interval of 33-59 months between two successive last births.

- Short birth interval: the birth interval less than 33 months between consecutive births.

- Optimum birth interval: the birth interval of 33 to 59 months between two successive births.

- Index Child: - the child first born to mother

- Wealth Index- is a composite measure of the cumulative living standard of a household. The wealth index is calculated using easy-to-collect data on a household's ownership of selected assets, such as televisions and radio, materials used for housing construction and types of water access and sanitation facilities.

1.6. Conceptual Frame work

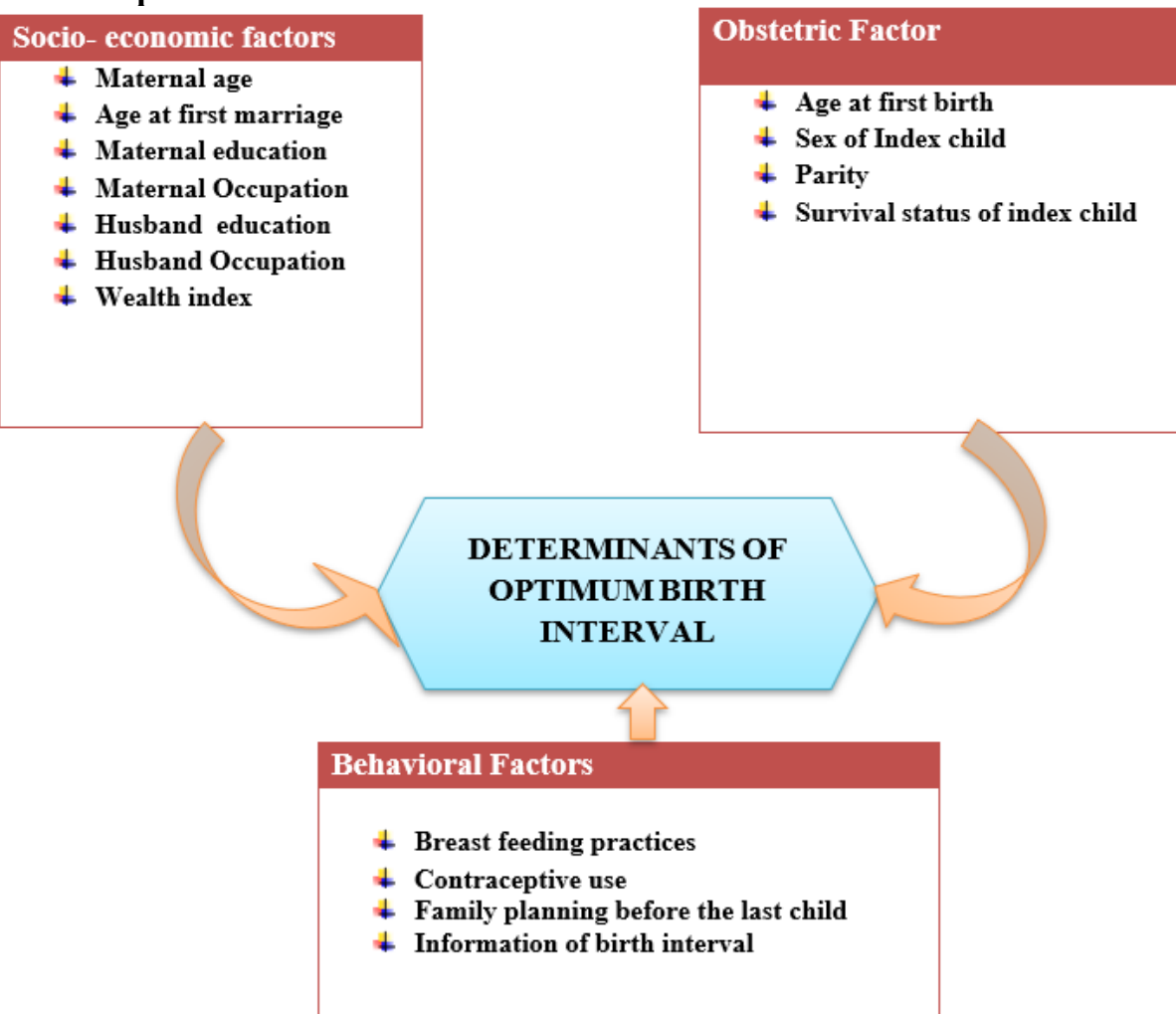

Figure 1:-Conceptual frame work on potential determinants of birth interval among married women of child bearing, constructed from different literatures. 


\section{Methodology}

\subsection{Study Area}

Becho woreda is found in Oromia region, Southwest Showa zone. It is located $82 \mathrm{~km}$ far away from Addis Ababa. It is one of the eleven woredas found in the zone. The woreda has 22 rural and 4 urban kebeles with a total population of 203,032 (male 100,305 Female 102,727). Women of child bearing age account 44,931. It is bounded by Dawo woreda in the north, Waliso woreda in the west, Illu woreda in the east and Saden Sodo woreda in the south. It has semi highland agro ecological environment. It is situated at 1800-2950 meters above sea level and has an average temperature ranging from $10^{\circ \mathrm{cc}}$ to $24^{\mathrm{oc}}$. The annual rain fall is $1250 \mathrm{~mm}$ per year. More than $95 \%$ of the population is engaged in agriculture. There are 26 schools of all type. Regarding health care facility, the district has one hospital, four health centers and 22 health posts operating currently.

\subsection{Study Design and Period}

Community based case control study was conducted from July to October 2019.

\subsection{Population}

\subsubsection{Source population}

All the married women of child bearing age who experienced at least two consecutive deliveries in the last five years prior to the data collection period.

\subsubsection{Study Population}

Randomly selected married women of child-bearing age living in the Woreda who have at least two consecutive births and the last delivery being within the past five years prior to the survey.

\subsection{Inclusion and Exclusion Criteria}

\subsubsection{Inclusion Criteria:}

(I) For controls: Married women who gave two live birth within the last 59 months and have at least two consecutive live births with birth interval of 33-59 months between the last two successive live births were included.

(II) For cases: Married women who gave two live birth within the last 59 months and have at least two consecutive live births with birth interval of less than 33 months between the latest two successive live births were excluded.

\subsubsection{Exclusion criteria:}

Clients who are seriously ill, unable to communicate and mentally ill during the data collection period were excluded from the study.

\subsection{Sample Size Determination and Sampling Techniques 3.5.1. Sample size Determination}

The sample size was determined by the formula used for unmatched case control study using Open EPI INFO version 7.3.5 software by taking in account of the major determinant factors. Accordingly, a minimum detectable OR (Odds Ratio) of 2, a 5\% level of precision, a power of $80 \%$, and a two-to-one allocation ratio of optimum birth interval (controls) to low birth interval (cases) was assumed. An additional non-response rate of $10 \%$ was also considered. The proportion of short birth interval $(66 \%)$ was chosen as dependent variables since it gave a maximum sample size. (Desta Hailu et.al, 2016). Design effect of 1.5 was also considered. Based on the above assumptions, the final sample size was determined to be 693 (231 cases and 462 controls). Proportion of short birth interval was chosen as dependent variables since it gave a maximum sample size. Table 1 
Table 2: Sample size determination Using Epi Info 7.3.5 for dependent variable (short Birth interval)

StatCalc

StatCalc - Sample Size and Power

Unmatched Case-Control Study (Comparison of ILL and NOT ILL)

Two-sided confidence level:

Power:

Ratio of controls to cases:

Percent of controls exposed:

Odds ratio:

Percent of cases with exposure:
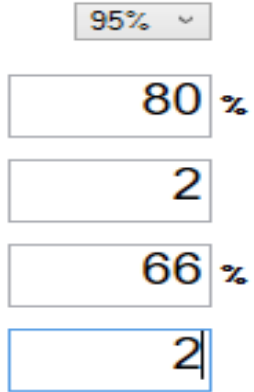

$79.5 \%$

\begin{tabular}{|c|c|c|c|}
\cline { 2 - 4 } \multicolumn{1}{c|}{} & Kelsey & Fleiss & $\begin{array}{c}\text { Fleiss } \\
\text { w/ CC }\end{array}$ \\
\hline Cases & 134 & 130 & 140 \\
\hline Controls & 268 & 259 & 280 \\
\hline Total & 402 & 389 & 420 \\
\hline
\end{tabular}

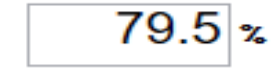

\subsection{Sampling Procedure and Technique}

From twenty-seven kebeles of Becho woreda nine kebeles were selected by simple random sampling. Then, house to house visit (census) was conducted in all the selected kebeles to identify women who fulfill the inclusion criteria (cases and controls) by having registered the birth date of the last two children of a family with their corresponding household identification number. One thousand eight hundred eight cases and four thousand three hundred ninety-three controls were identified. To determine children's birth dates, immunization cards were used. For those who were not immunized, community based health extension workers were consulted and CHIS was referred. Using respective household identification number, frames of households containing study subjects defined as cases and controls were prepared for each kebele. Systemic random sampling was used to determine the study participants from each kebele as well as cases and controls. Finally, child-bearing age women who had at least two consecutive live births and whose last delivery was within the past five years prior to the survey were selected using systematic random sampling technique from the existing sampling frame. Whenever more than one eligible respondent was found in the same selected household, only one respondent was chosen by lottery method. For participants who were not present at the time of data collection, at least two revisits were made to trace them. Fig 2

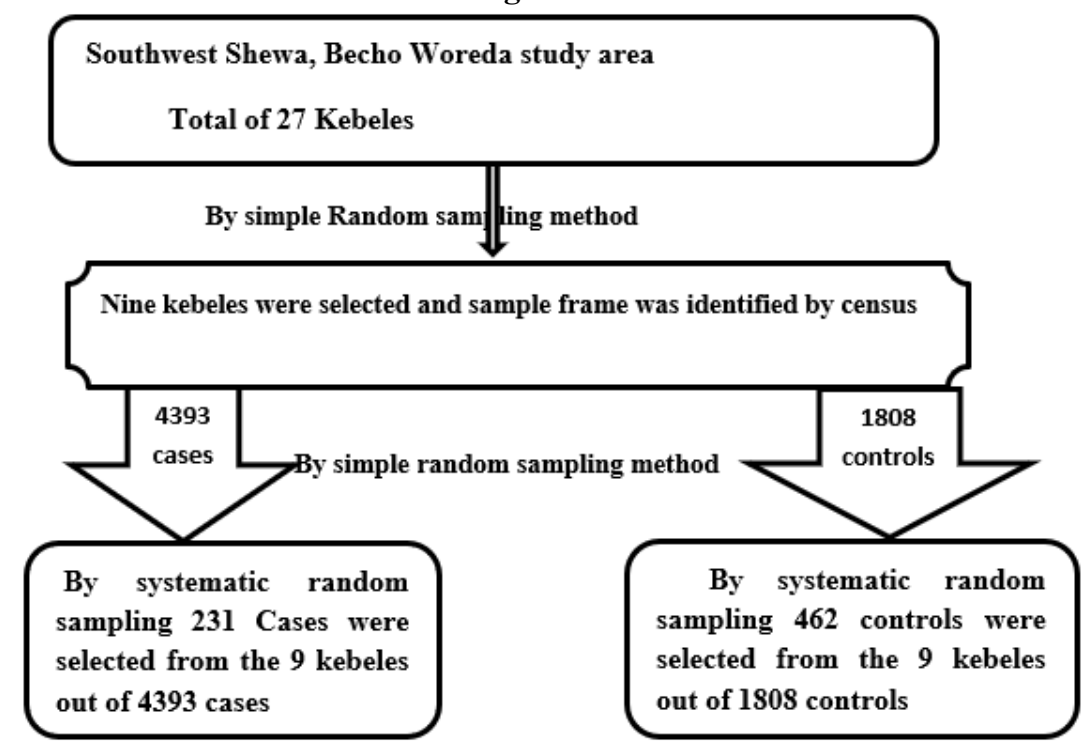

Figure 2: Schematics diagram indicating sampling procedure. 


\subsubsection{Dependent variable}

Short birth interval

\subsubsection{Independent variables}

Socio-Demographic and economic variables: Age of mother, mother of education, husband education, place of residence; ethnicity, religion, occupation of mother, occupation of husband, wealth index.

Obstetric Variables: age at first marriage, the survival status of the index child, sex of index child, parity, history of abortion, history of still birth.

Behavioral variables: breast feeding practice, contraceptive use, previous pregnancy plan.

\subsection{Data Collection}

\subsubsection{Data Collection Instrument}

First, the questionnaire was prepared in English and translated to afaan Oromo to make data collection process simple and translated back to English language to check its consistency. Then questionnaire was pre- tested by taking 5 percent ( 35 women) of the sample size on similar but different setting and necessary modification in the questionnaire was made based on the gaps identified. A two days training was given for data collectors and supervisors on how to gather the appropriate information, procedures of data collection techniques and the whole contents of the questionnaire. The data collectors were trained agricultural development army.

\subsubsection{Data collection Procedure}

This study obtained data from the interviews of mothers residing in sampled households. Structured and pretested questionnaire was employed to obtain information on obstetric history, socioeconomic status, contraception use, breast-feeding practice, and attitude towards birth spacing and family planning. The questionnaire was adopted from different previously done studies and adapted to the local context of the study area. It was prepared first in English and then translated to Afaan Oromo by the language expert for the data collection purpose. To check its consistency, the questionnaire was translated back to English by another language expert. Four agriculture development army who were familiar with the local language and customs were recruited as interviewers. One B.S. degree holding teacher were supervised the data collection process. Data collectors and supervisors were trained for two days on census procedures, questions included in the questionnaire, interview techniques, and importance of privacy and confidentiality of the information obtained from the respondents. Before conducting the main study, pretest was carried out on $5 \%$ of the sample size (18 cases and 18 controls) from one kebele, which was not included in the main study. Based on the result, data collectors were reoriented and the questionnaire was modified as appropriate. Data collected from each respondent were checked for completeness, clarity, and consistency by the principal investigator and the supervisors at the end of each data collection day.

\subsection{Data Quality control}

First, the questionnaire was translated to Afaan Oromo to make data collection process simple and translated back to English language to check its consistency. Then questionnaire was pre- tested by taking 5 percent ( 35 women) of the sample size on similar but different setting and necessary modification in the questionnaire was made based on the gaps identified. A two days training was given for five data collectors and two supervisors on how to gather the appropriate information, procedures of data collection techniques and the whole contents of the questionnaire. The data was collected by trained agricultural development army using a structured and pretested questionnaire prepared in Afaan Oromo. A day today on site supervision was carried out during the whole period of data collection by supervisors (teachers). At the end of each day, the questionnaire was checked for completeness, accuracy and consistency by the supervisors and investigator and corrective discussion was under taken with all the data collectors and the supervisors. Data was entered, cleaned and edited by using the SPSS version 22 software.

\subsection{Data Analysis}

Data was coded, entered and cleaned by using SPSS version 22 and analyzed by using descriptive, bivariate and multivariate techniques and $95 \%$ confidence levels were used in identifying important determinant variables of independent variables. Descriptive analysis of the determinant of birth interval for WCBA was carried out by Univariate analysis. Bivariate analysis of the birth interval with all selected independent variables was done to see their differentials. It will also be done to see the presence of significant association between dependent and independent variables. Multiple logistic regression analysis was done for variables with significant association during bivariate analysis with P-value of $\leq 0.025$ as an important predictors of the short birth interval.

Determinant of short birth interval was measured in this study by measuring the strength of association of factors that can contributes to the short birth interval among married child bearing women in the study area. In this specific study some determinants have been mentioned on the conceptual frame work. So for each factors given on the conceptual frame work possible numbers of question was interviewed. 


\subsection{Ethical Considerations}

Prior to data collection appropriate ethical clearance was obtained from the ethical clearance committee of the Madda Walabu University. Formal letter of permission was gained from administrative bodies of Bale zone to the woreda and to kebeles. Letter of cooperation from kebele administrators was also be secured. Verbal informed consent was requested from every study participant included in the study during data collection time after explaining the objectives of the study. Finally, confidentiality will also be assured for the information provided since the name of the information provider will not be stated on the questionnaire rather coding system was applied

\section{Result}

\subsection{Demographic and socioeconomic characteristics of respondents}

Six hundred ninety-three child-bearing age women who had at least two live births in last five years were interviewed making a response rate of $100 \%$. The mean age of the respondents was 32 years $(\mathrm{SD} \pm 4.6)$. Seventyeight (33.8) of the cases and 206 (44.6) of the controls were within the age range of 30-34 years (figure 3). The majority (128) (55.4) of the cases and 252 (54.5) of the controls were married at the age of 18 years or less. Regarding educational status, one hundred seventy-seven (76.6) of the cases and 189 (40.9) controls had not attended formal education. The poorest wealth index was computed at 79 (34.2) and 114 (24.7) in the cases and controls, respectively (Table 3 ).

Table 3: Demographic and socioeconomic characteristics of birth interval among married child bearing women in Becho Woreda, Oromia regional state, Ethiopia, $2019(n=693)$.

\begin{tabular}{lcc}
\hline Variables & Case Number (\%) & Control Number (\%) \\
Maternal Age group & $13(5.6)$ & \\
$17-24$ & $32(13.9)$ & $17(3.7)$ \\
$25-29$ & $\mathbf{7 8}(\mathbf{3 3 . 8})$ & $\mathbf{2 0 6}(\mathbf{4 4 . 6 )}$ \\
$\mathbf{3 0 - 3 4}$ & $\mathbf{1 0 8}(\mathbf{4 6 . 8})$ & $\mathbf{1 0 4}(\mathbf{2 2 . 5})$ \\
$>=\mathbf{3 5}$ & & \\
Maternal marriage age group & $128(55.4)$ & $252(54.5)$ \\
$12-18$ & $97(42)$ & $188(40.7)$ \\
$19-24$ & $6(2.6)$ & $22(4.8)$ \\
$25-29$ & & \\
Maternal educational status & $177(76.6)$ & $189(40.9)$ \\
No education & $37(16)$ & $236(51.1)$ \\
Primary school & $17(7.4)$ & $37(8.0)$ \\
Secondary school and above & & \\
Wealth index & $79(34.2)$ & $170(36.8)$ \\
Poorest & $62(26.8)$ & $164(35.5)$ \\
Second & $54(23.4)$ & $80(17.3)$ \\
Middle & $36(15.6)$ & $48(10.4)$ \\
Fourth &
\end{tabular}

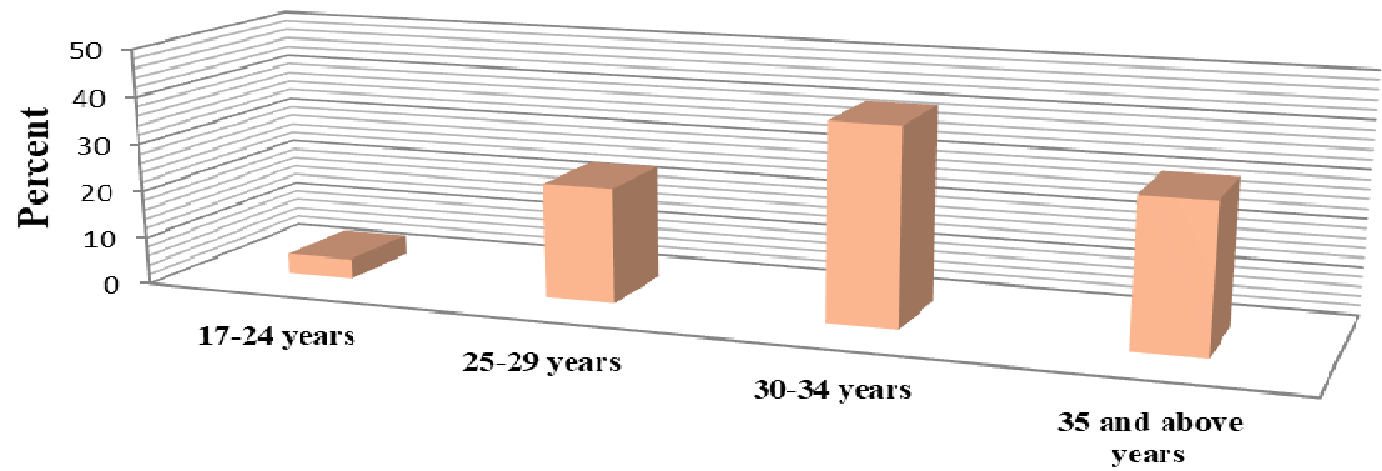

Maternal age group

Figure 3: -Shows the maternal age group among married child bearing women in Becho Woreda, Oromia Regional state, 2019 G.C. 


\subsection{Obstetric Factor}

The finding of this study show that $99(30.7 \%)$ of cases and $176(38.1 \%)$ controls have not well defining the short birth interval. One hundred six (45.9\%) of the cases and 250(54.1\%) controls were reported to have three up to four live children (Figure 4$)$. Twenty one $(9.1 \%)$ of the cases and $14(3.0 \%)$ of the controls had died child between the last two live births. One hundred thirteen $(48.9 \%)$ and $340(73.6 \%)$ of cases and controls, respectively, had planned pregnancy. The majority (201) (87.0\%) of the cases breast fed for less than 24 months, while $411(89.0 \%)$ of the controls breast-fed for 24 months or above (Figure 4). Seventy (30.3\%) of the cases and $328(71.1 \%)$ of the controls utilized modern contraceptive method after the delivery of the preceding child but before they got pregnant with the last child (Table 4).

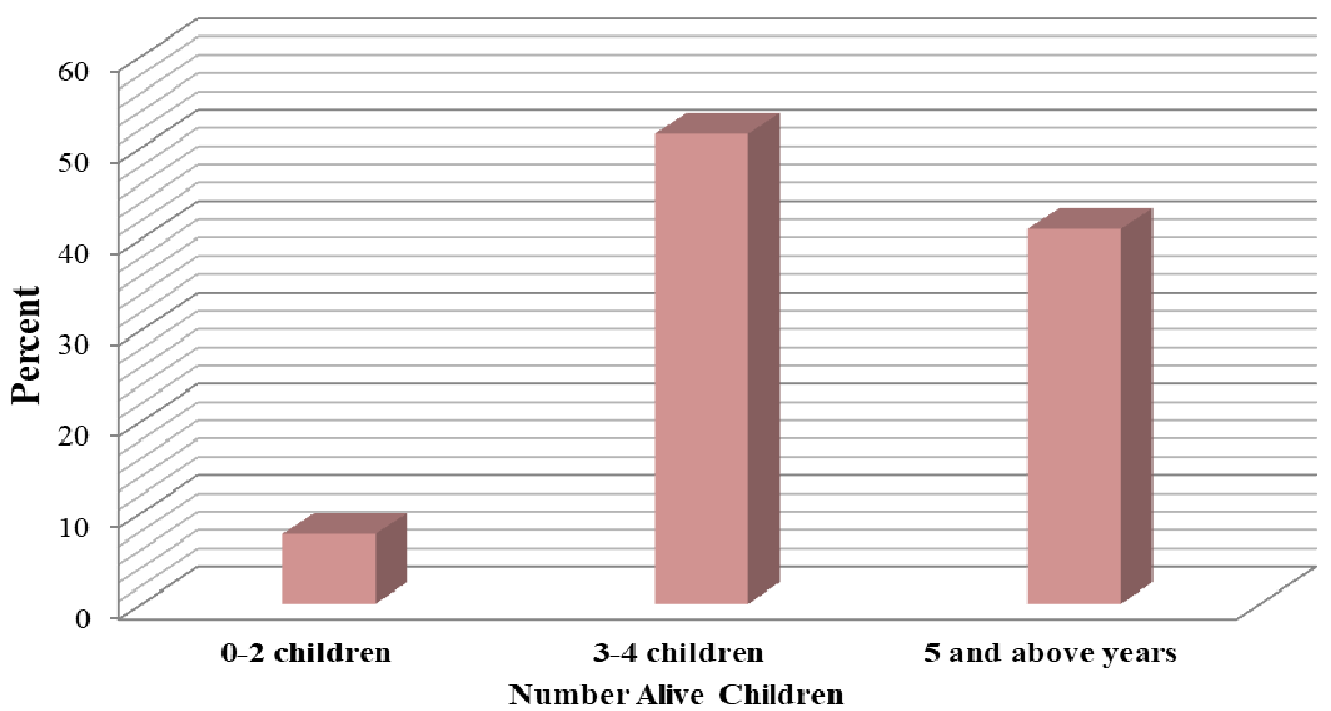

Figure 4:- Shows the number alive children among married child bearing women in Becho woreda, Oromia Regional state, Ethiopia, 2019 G.C.

Table 4: Obstetric variables of mothers among married child bearing women in Becho Woreda, Oromia regional state, Ethiopia, $2019(\mathrm{n}=693)$.

\begin{tabular}{lll}
\hline Variables & Case Number (\%) & Control Number (\%) \\
Number of living children & $26(11.3)$ & $27(5.8)$ \\
$0-2$ & $106(45.8)$ & $250(54.1)$ \\
$3-4$ & $99(42.9)$ & $185(40)$ \\
5 and above children & & \\
Sex of the preceding child & $165(71.4)$ & $168(36.4)$ \\
Female & $66(28.6)$ & $294(63.6)$ \\
Male & & \\
Status of the preceding child & $210(90.9)$ & $448(97.0)$ \\
Alive & $21(9.1)$ & $14(3.0)$ \\
Dead & $113(48.9)$ & $340(73.6)$ \\
Previous pregnancy plan & $118(51.1)$ & $122(26.4)$ \\
yes & & $328(71.0)$ \\
No & $70(30.3)$ & $134(29.0)$ \\
Contraceptive use before last pregnancy & $16169.7)$ & \\
Yes & $139(60.2)$ & $279(60.4)$ \\
No & $92(39.8)$ & $183(39.6)$ \\
Mother correctly defines optimal birth interval & $12(2.6)$ \\
Yes & & $39(8.4)$ \\
No & $24(10.4)$ & $411(89)$ \\
Duration of breast-feeding & $177(76.6)$ & \\
$0-11$ months & $30(13.0)$ & \\
$12-23$ months & & \\
>=24 months & & \\
\hline
\end{tabular}




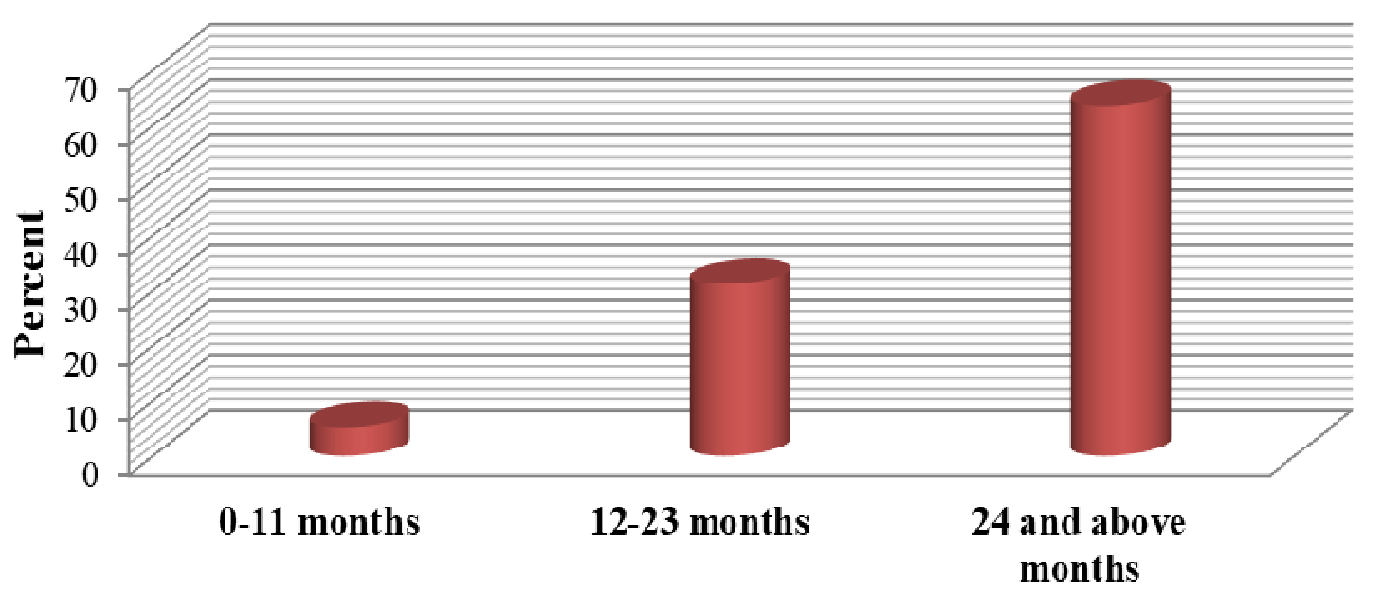

Duration of breast feeding

Figure 5: Shows the duration of breast feeding among married child bearing women in Becho woreda, Oromia Regional state, Ethiopia, 2019 G.C.

\subsection{Bi-variate analysis}

Binary logistic regression was done for obstetric factors, age of mother, educational status of the mother, and wealth index of the respondents showed that significant association with short birth interval. The odds of experiencing short birth interval were higher for mothers who were not educated or unable to read and write as compared to those who attended formal education. Similarly, as wealth index of respondents decreased, the likelihood of having short birth interval was high (Table 5).

On bivariate analysis, duration of breast feeding for the preceding child, sex of the preceding child, pregnancy plan for the last child, contraceptive utilization before getting pregnant for the last child had showed significant statistical association with short birth interval. Female sex of the preceding child was positively associated with experiencing short birth interval. Similarly, the odds of experiencing short birth interval were about 8 times higher for mothers who did not have pregnancy plan for their last child than those who had a plan to get pregnant. Mothers who did not use modern contraceptive method before getting pregnant with the last child were 9 times more likely to experience short birth interval as compared to those who used it. Duration of breast-feeding of the preceding child had also showed significant statistical association. The odds of having short birth interval were about 4 times higher for mothers who breast-fed their preceding child for less than 24 months as compared to their counter parts who breast-feed for 24 months or more (Table 5). 
Table 5: Bivariate analysis of socioeconomic characteristics, obstetric factors, breast-feeding, and contraception history of child-bearing age women in Becho Woreda, Oromia regional state, Ethiopia, 2019 (n=693).

\begin{tabular}{|c|c|c|c|c|}
\hline \multirow{2}{*}{$\begin{array}{l}\text { Variables } \\
\text { Maternal Age group }\end{array}$} & & \multirow[b]{2}{*}{$\begin{array}{l}\text { Control } \\
(\%)\end{array}$} & Crude $\quad$ Odds & \multirow[b]{2}{*}{$p$ value } \\
\hline & $\begin{array}{l}\text { Case } \\
(\%)\end{array}$ & & Ratio(95\%CI) & \\
\hline $17-24$ & $13(5.6)$ & $17(3.7)$ & $0.81(0.32-2.05)$ & 0.0001 \\
\hline $25-29$ & $32(13.9)$ & $135(29.2)$ & $0.74(0.30-1.81)$ & 0.655 \\
\hline $30-34$ & $78(33.8)$ & $206(44.6)$ & $2.57(1.06-6.24)$ & 0.504 \\
\hline$>=35$ & $108(46.8)$ & $104(22.5)$ & 1 & \\
\hline \multicolumn{5}{|c|}{ Maternal educational status } \\
\hline No education & $177(76.6)$ & $189(40.9)$ & 17.34(10.09-29.81) & 0.0001 \\
\hline Primary school & $37(16)$ & $236(51.1)$ & $80.25(35.28-182.56)$ & \\
\hline $\begin{array}{l}\text { Secondary school and } \\
\text { above }\end{array}$ & $17(7.4)$ & $37(8.0)$ & 1. & \\
\hline \multicolumn{5}{|l|}{ Wealth index } \\
\hline Poorest & $79(34.2)$ & $170(36.8)$ & $0.17(0.09-0.31)$ & 0.0001 \\
\hline Second & $62(26.8)$ & $164(35.5)$ & $2.77(1.79-4.27)$ & 0.0001 \\
\hline Middle & $54(23.4)$ & $80(17.3)$ & $2.22(1.34-3.67)$ & 0.002 \\
\hline Fourth & $36(15.6)$ & $48(10.4)$ & 1 & \\
\hline \multicolumn{5}{|l|}{ Sex of the preceding child } \\
\hline Female & $165(71.4)$ & $168(36.4)$ & $9.51(6.46-13.99)$ & 0.0001 \\
\hline Male & $66(28.6)$ & $294(63.6)$ & 1 & \\
\hline \multicolumn{5}{|l|}{ Previous pregnancy plan } \\
\hline Yes & $113(48.9)$ & $340(73.6)$ & $8.43(5.88-12.06)$ & 0.0001 \\
\hline No & $118(51.1)$ & $122(26.4)$ & 1 & \\
\hline \multicolumn{5}{|c|}{ Contraceptive use before last pregnancy } \\
\hline Yes & $70(30.3)$ & $328(71.0)$ & $9.86(6.94-14.01)$ & 0.0001 \\
\hline No & 16169.7) & $134(29.0)$ & 1 & \\
\hline \multicolumn{5}{|l|}{$\begin{array}{l}\text { Duration of breast- } \\
\text { feeding }\end{array}$} \\
\hline $0-11$ months & $24(10.4)$ & $12(2.6)$ & $0.39(0.18-0.83)$ & 0.014 \\
\hline $12-23$ months & $177(76.6)$ & $39(8.4)$ & $0.28(0.13-0.58)$ & 0.001 \\
\hline$>=24$ months & $30(13.0)$ & $411(89)$ & 1 & \\
\hline
\end{tabular}

\subsection{Multivariable analysis of factors affecting short birth interval}

To identify the determinants of short birth interval of the last two children born to the study participants, bivariate and multivariate analysis was carried out. In multivariable logistic regression analysis, previous pregnancy plan, educational status of the mother, contraceptive utilization, duration of breast-feeding, sex of the preceding child, age during delivery of the last child, and wealth index were found to be independent predictors of short birth interval (Table 5). Level of education of mother for cases and controls showed that strong statistical association with short birth interval. Mothers with no formal educational were about 2 times [(AOR = 2.040, 95\% CI: $(1.497-2.778)]$; $p$-value $=0.0001)$ more likely to have short birth interval as compared to those who attended formal education (table 6).

The other strong predictor of short birth interval was utilization of contraceptive methods. The odds of having short birth interval were seven times among mothers who did not use modern contraceptive method before getting pregnant with the last child [(AOR=7.075,95\% CI:(5.034-9.942)]; p-value=0.0001) than those who used modern contraceptive method.

Similarly, mothers who breast-fed the preceding child for less than 24 months were more than two times to have short birth interval than their counterparts of mothers who breast-fed for 24 months or more [(AOR:0.61,95\% CI (0.446-0.838)]; p-value=0.0001). Sex of the preceding child has also revealed a significant association with short birth interval. Mothers whose preceding birth was female were about 7 times [(AOR: 7.695, 95\% CI (5.240-11.301)]; p-value $=0.0001$ more likely to experience short birth interval than those whose child was male. Wealth index of the mother was also a strong predictor of short birth interval. The odds of having short birth interval were more than three times for mothers who belong to the poorest wealth index than the richest ones $[(\mathrm{AOR}=3.080,95 \% \mathrm{CI}(1.846-5.139)]$; $\mathrm{p}$-value $=0.0001$. 
Table 6: Multivariate analysis of determinant factors among child-bearing age women in Becho Woreda, Oromia regional state, Ethiopia, 2019 ( $\mathrm{n}=693)$.

\begin{tabular}{|c|c|c|c|c|c|}
\hline \multicolumn{6}{|l|}{ Variables } \\
\hline $\begin{array}{l}\text { Age at delivery of the } \\
\text { last child }\end{array}$ & $\begin{array}{l}\text { Case No. } \\
(\%)\end{array}$ & $\begin{array}{l}\text { Control No. } \\
(\%)\end{array}$ & $\operatorname{COR}(95 \% \mathrm{CI})$ & $\operatorname{AOR}(95 \% C I)$ & $\begin{array}{l}p \\
\text { value }\end{array}$ \\
\hline $17-24$ & $13(5.6)$ & $17(3.7)$ & $\begin{array}{l}0.8090(0.320- \\
2.045)\end{array}$ & $\begin{array}{l}0.455(0.203- \\
1.018)\end{array}$ & 0.055 \\
\hline 25-29 & $32(13.9)$ & $135(29.2)$ & $0.736(0.300-1.808)$ & $\begin{array}{l}1.358(0.901- \\
2.047)\end{array}$ & 0.144 \\
\hline 30-34 & $78(33.8)$ & $206(44.6)$ & $2.568(1.056-6.243)$ & $\begin{array}{l}2.060(1.424- \\
2.980)\end{array}$ & 0.0001 \\
\hline$>=35$ & $108(46.8)$ & $104(22.5)$ & 1 & 1 & \\
\hline \multicolumn{6}{|l|}{ Education of Mother } \\
\hline No formal education & $177(76.6)$ & $189(40.9)$ & $\begin{array}{l}17.339(10.085- \\
29.811)\end{array}$ & $\begin{array}{l}2.040(1.497- \\
2.778)\end{array}$ & 0.0001 \\
\hline Has formal education & $54(23.4)$ & $273(59.1)$ & 1 & 1 & \\
\hline \multicolumn{6}{|c|}{ Sex of the preceding child } \\
\hline Female & $165(71.4)$ & $168(36.4)$ & $\begin{array}{l}9.508(6.461- \\
13.991)\end{array}$ & $\begin{array}{l}7.695(5.240- \\
11.301)\end{array}$ & 0.0001 \\
\hline Male & $66(28.6)$ & 294(63.6) & 1 & & \\
\hline \multicolumn{6}{|c|}{ Occupation of the mother } \\
\hline House wife & 207(89.6) & $440(95.2)$ & $1.599(0.627-4.076)$ & $\begin{array}{l}8.734(2.975- \\
25.643)\end{array}$ & 0.002 \\
\hline Merchant & $13(5.6)$ & $7(1.5)$ & 4.049(1.823-8.994) & $\begin{array}{l}31.167(6.136- \\
58.317)\end{array}$ & 0.0001 \\
\hline Farmer & $11(4.8)$ & $15(3.2)$ & 1 & & \\
\hline $\begin{array}{l}\text { Previous pregnancy } \\
\text { plan }\end{array}$ & & & & & \\
\hline Yes & $113(48.9)$ & $340(73.6)$ & $\begin{array}{l}8.427(5.887- \\
12.064)\end{array}$ & $\begin{array}{l}8.595(6.018- \\
12.177)\end{array}$ & 0.0001 \\
\hline No & $118(51.1)$ & $122(26.4)$ & 1 & & \\
\hline \multicolumn{6}{|c|}{ Contraceptive use before last pregnancy } \\
\hline Yes & $70(30.3)$ & $328(71.0)$ & $\begin{array}{l}9.858(6.938- \\
14.007)\end{array}$ & $\begin{array}{l}\text { 7.075(5.034- } \\
9.942)\end{array}$ & 0.0001 \\
\hline No & 16169.7) & $134(29.0)$ & 1 & & \\
\hline \multicolumn{6}{|l|}{$\begin{array}{l}\text { Duration of breast- } \\
\text { feeding }\end{array}$} \\
\hline$<24$ months & 201(87.0) & $51(11.0)$ & $0.276(0.132-.575)$ & $\begin{array}{l}0.612(0.446- \\
0.838)\end{array}$ & 0.0001 \\
\hline$\geq 24$ months & $30(13.0)$ & $411(89.0)$ & 1 & 1 & \\
\hline \multicolumn{6}{|l|}{ Wealth index } \\
\hline Poorest & $79(34.2)$ & $170(36.8)$ & $0.172(.098-.301)$ & $\begin{array}{l}3.080(1.846- \\
5.139)\end{array}$ & 0.0001 \\
\hline Seconded & $62(26.8)$ & $164(35.5)$ & $2.768(1.795-4.268)$ & $\begin{array}{l}8.868(5.020- \\
15.665)\end{array}$ & 0.0001 \\
\hline Middle & $54(23.4)$ & $80(17.3)$ & $2.216(1.339-3.667)$ & $\begin{array}{l}0.510(0.282- \\
0.922)\end{array}$ & 0.026 \\
\hline Fourth & $36(15.6)$ & $48(10.4)$ & 1 & 1 & \\
\hline
\end{tabular}

\section{Discussion}

This community based case control study identified factors influencing short birth interval among mothers who had at least two live births with their last child born within the last five years in Becho District, Oromia, Ethiopia. Result of this study revealed that majority of respondents 501(72.3\%) have short birth interval, only 192(27.7\%) have optimal birth interval. According to this study result short birth interval is higher than similar studies conducted in Pakistan 49.2\%, Tanzania 50.8\%, southern of Ethiopia Yabello 68.8\%, Arba Minch Zuria 69.2\% (Rasekh, 2016)(Mrema et al., 2015)(Begna et al., 2013a)). However the finding of this study is higher than national coverage of short birth interval which is $67.6 \%$, Tselemti district $66.2 \%$ and Oromia region, Dodota woreda $68.5 \%$ (Hailu and Gulte, 2016) ). This could be explained by the fact that women are lack of awareness and have less autonomy to make decisions and use of family planning services. 
Even though no statistical association was revealed, the majority of the respondents defined short birth interval correctly. In this study, the odds of having short birth interval were higher among mothers who had no formal education as compared to their women counter parts who attended formal education. This finding is consistent with evidences from study conducted in Saudi Arabia, Nepal, Jordan, Ahvaz (Iran), and Pakistan (Youssef, 2006)(Kamal and Pervaiz, 2012)(Rasekh, 2016). Finding of this study (AOR = 2.040, 95\% CI: (1.4972.778) $\mathrm{p}$-value $=0.0001$ ) is also higher than similar study done in southern Ethiopia, Yabello, Arba Minch Zuria and northern Ethiopia, Tselemti district (Hailu and Gulte, 2016)(Begna et al., 2013a)).This can be partly explained by the fact that educated women are well informed about optimal health care choices and have greater autonomy to make decisions and use quality health care services.

In line with evidences from studies done in Tanzania, Kenya, Ghana and Egypt, the finding of the present study $(\mathrm{AOR}=7.075,95 \% \mathrm{CI}:(5.034-9.942)$; $\mathrm{p}$-value $=0.0001)$ indicated that mothers who did not utilize modern contraceptive method before they got pregnant with their last child were seven times higher to experience short birth interval than those who used one (Mrema et al., 2015)(Ofosu, Akoto and Agbi-dzorkar, 2014)(Abdel-tawab and Loza, 2018)(Awiti, 2015)(Bedane, 2016). This is the fact that not using of modern contraceptive is highly predictor of short birth interval.

The finding of the present study revealed that the odds of having short birth interval (AOR: $7.695,95 \%$ CI (5.240-11.301); $\mathrm{p}$-value $=0.0001)$ more than seven times whose preceding birth was female than mothers who had males. Study findings from Manipur, Saudi Arabia, Jordan, and Tanzania provided similar evidence (Youssef, 2014)(Kozuki et al., 2013). Similarly studies from Dabat District, Northwest Ethiopia and Dodota Woreda, Arsi Zone, Ethiopia preceding birth was female than mothers who had males were a significant factor associated with having short birth interval(Seifadin Ahmed Shallo and Tesfaye Goben, 2019)(Tessema et al., 2015). This may be attributed to the reason that a son is considered as a potential economic asset to the family as a whole and it is therefore less likely form others to exercise long time breastfeeding or utilize modern contraceptive method as a means of birth control until they get the desired number of sons.

Similarly, mothers who breast feeding the preceding child for less than 24 months were more than two times to have short birth interval than their counterparts of mothers who breast-fed for 24 months or more (AOR: $0.612,95 \%$ CI $(0.612(0.446-0.838)$; p-value $=0.0001)$. This study finding was congruent with evidences from Jordan, Tanzania, Kenya, Ghana, Egypt, and Nigeria. This is consistent with the study done in Southern and northern part of Ethiopia (Yoder, 2015)(Selin and Stone, 2014)(Kozuki et al., 2015)(Nti et al., 2014)(Towriss et al., 2018). It has been recognized that women who had breastfeed their children for longer duration have a longer period of amenorrhea which results in postpartum infecundability when compared to their counterparts. This may be also due to the fact that breast-feeding extends period of short birth interval through negative hormonal feedback.

Wealth index of the mother was also a strong predictor of short birth interval. Consistent with evidence from study done in Saudi Arabia, Lemo District, Ethiopia, the odds of having (AOR=3.08, 95\% CI; (1.84-5.13); $\mathrm{p}$-value $=0.0001)$ short birth interval were three time higher who belonged to the poorest wealth index than the fourth group of mothers(Hailu and Gulte, 2016)(Tessema et al., 2015). This can be partly explained by the fact that poorest women are less likely to access health care information and afford health, thus can easily apply scientifically recommended short birth interval.

\section{Strength and Limitation \\ 6.1. Strength}

The strength of this study can be, case-control study and systematic random sampling method used to decrease sampling bias. Response rate of the study were $100 \%$ obtained during data collection.

\subsection{Limitation}

When interpreting the finding of the present study, the following limitations should be considered. The source of data for this study was based on the self-report of mothers, and no validation of information was made with any objective sources such as health facility cards except for immunization cards of their children. But respondents were critically informed about the importance of giving accurate information by assuring the confidentiality of their responses and it is logical to assume that biases are less likely in birth interval related events as compared to other sensitive issues. There could be a recall bias since women were asked for information about events that occurred in the distant past though different life events were used to memorize them. This study considered only a single birth interval and therefore further researches, involving more than two inter birth intervals, should be done to make these findings more informative.

\section{Conclusion and Recommendation}

\subsection{Conclusion}

Short birth interval has great role on maternal and child mortality. However, birth interval of children varied with 
different socioeconomic, obstetric and behavioral factors of their families. Educational status of the mother, contraceptive utilization, duration of breast feeding, sex of the preceding child, age during delivery of the first child, and wealth index of respondents were independent predictors of short birth interval between the last two live births.

\subsection{Recommendation}

Thus, the Ethiopian Ministry of Health together with its stake holders should strengthen the existing strategies of providing information, education, and communication on impact short birth interval. Ministry of Health should work on women and their partner on creating awareness about the importance of modern contraceptive utilization, breast-feeding, and optimal birth interval. Health extension workers should work on the use of modern contraceptive. Police makers should work on the child spacing and balance use of natural resources. Moreover, this study considered only a single birth interval and therefore further researches, involving two and more birth intervals, should be done to make these findings more informative.

\section{References}

Al-Almaie, S. (2011). "The pattern and factors associated with child spacing in Eastern Saudi Arabia." JRSH 123(4): 217-22.

Conde-Agudelo A, R.-B. A., Kafury-Goeta AC (2006). "Birth spacing and risk of adverse perinatal outcomes: a meta-analysis." JAMA 295: 1809-1823.

Ethiopia CSA and ICF International. (2016). Ethiopia Demographic and Health Survey. Addis Ababa, Ethiopia and Calverton, Maryland, USA: Central Statistical Agency and ICF International.

Exavery A, M. S., Shamte A, Bietsch K, Mosha D, et al. (2012). "Levels and correlates of non-adherence to WHO recommended inter-birth intervals in Rufiji, Tanzania." BMC Pregnancy and Childbirth 12: 152.

FD, A. (2015). "A systematic review and meta-analysis of the effect of short birth interval on infant mortality in Ethiopia." PLOS ONE 10: 1.

Gizachew Assefa Tessema, B. M. Z. a. T. A. A. (2016). "Birth interval and its predictors among married women in Dabat District, Northwest Ethiopia." A retrospective follow-up study; Afr J Reprod Health 2013 17[2] (39-45).

Gobena, S. A. S. a. T. (2019). "Duration of Birth Interval and Associated Factors among Married Women in Dodota Woreda, Arsi Zone, Ethiopia." Health Educ Res Dev (7:1).

Gulte, D. H. A. T. (2016). "Determinants of Short Inter Birth Interval among Reproductive Age Mothers in Arba Minch District, Ethiopia;" Article ID 60243, ; volume 201, : 5-17 pages.

Khalid, K. A. a. P. M. (2013). "Determinants of higher order birth intervals in Pakistan." Journal of Statistics vol. 19: pp.54-82.

Kozuki N, L. A., Silveira MF, Victora CG, Adair L, et al. (2013). "The associations of birth intervals with smallfor gestational-age, preterm, and neonatal and infant mortality: a meta-analysis." BMC Public Health vol. 13: S3.

M., N. (2013). "New evidence on birth spacing: promising findings for improving newborn, infant, child, and maternal health." Int J Gyn Obs; vol.89: 51-56.

M.Abdel-Fattah, T. H., T.I. ElSaid, M.M. Moharam, and M.A. Mahmoud (2017). "Determinants of birth spacing among Saudi women." Journal of Family and Community Medicine vol.14 (no. 3): pp.103-111.

Majid, R. A. a. M. (2014). "The determinants of birth interval in Ahvaz- Iran." A graphical chain modeling approach. J Da t Sc vol.5: pp 55-57.

Mtur, J. A. (2012). "The determinants of birth intervals among non-contraceptive user Tanzanian women." Union for African Population Studies vol.12.

Nahla Abdel-Tawab, S. L. a. A. Z. (2015). "Helping Egyptian women achieve optimal birth spacing intervals through fostering linkages between family planning and maternal/child health services." Journal of Family and Community Medicine vol.9.

Negussie, A. A. (2014). "Proximate determinants of birth interval length in Amhara region: the case of Fagita Lekoma woreda, Awi- zone." published M.Sc thesis Addis Ababa, Ethiopia Jun. 6:9.

Nti CA, G. C., Sarah NA, Ofosu B, Akoto E, et al. (2014). "Knowledge, Attitude and Practice of Birth Spacing among Ghanaian." vol.12.

Ogunlade, K. O. a. O. (2015). "Breast feeding and child spacing among women in South West Nigeria." International Journal for Cross-Disciplinary Subjects in Education vol. 2(no. 2): pp. 414- 421.

Organization, W. H. (2015). "Report of a WHO technical consultation on birth spacing." Geneva, Switzerland 13-15 June 2015.

Rafali manana, H. a. C. F. W. (2011). "Gap between Preferred and Actual Birth Intervals in Sub-Saharan Africa" Implications for Fertility and Child Health vol.15.

S, R. (2016). "Further Evidence of the Effects of Preceding Birth Intervals on Neonatal, Infant, and Under-Five- 
Years Mortality and Nutritional Status in Developing Countries." Evidence from the Demographic and Health Surveys vol. 6.

Samuel Yohannes, M. W., Mulumebet Abera and Eshetu Girma (2015). "Duration and determinants of birth interval among women of child bearing age in Southern Ethiopia." PubMed: pp 11-38.

Saumya Rama Rao, J. T. a. I. A. (2014). "Correlates of Inter-Birth Intervals: Implications of Optimal Birth Spacing Strategies in Mozambique." Population Council vol. 3.

Singh SN, N. R. (2011). "Demographic and Socio-economic Determinants of Birth Interval Dynamics in Manipur." A Survival Analysis Online Journal of Health Allied Sciences vol. 9: 1-5.

Teklu H, S. A., Gebreselassie T (2014). "Components of Fertility Change in Ethiopia: Further Analysis of the 2000, 2005, and 2011 Demographic and Health Surveys " ICF International 1. 